\title{
Prevalence of Musculoskeletal Discomfort in Bank Employees
}

\author{
Shweta Kotwani, Nikita Sinha, Vrushali Panhale \\ M.G.M College of Physiotherapy, Navi Mumbai \\ Address of correspondence - shweta.kotwani31528@gmail.com
}

\section{Introduction}

Work related musculoskeletal disorders of upper extremities are disabling and which can be prevented. (Pingle, 2002)

Who estimates that occupational health risks is the 10th leading cause of mortality and morbidity it adds on to the global burden of disease as it adds to the cost of work productivity in various countries due to increase use of medical and welfare services costing the economy $2-14 \%$ of the GDP(Leigh, Macaskill, Kuosma, \& Mandryk, 1999).

India is a vast country with a population of 1.025 billion in 2001 out of that 40 million belong to the working population(Pingle, 2002) out of that the bank employees are approximately 1 million as per 2007 reports(“India's Top Banks - Listing,” n.d.).

Bank professionals engaged as cashiers or other professionals may be exposed to repetitive trauma and stress causing exhaustion and neuromuscular damage due to repetition of their wrist, elbow and shoulder joints movement constantly working in front of the computer or standing (Lacerda et al., 2005).

Repetitive tasks when done for a long period of time can cause a negative impact on the optimum functioning of the body.

Musculoskeletal injurie classify as a major component to work related absenteeism and personal costs to the employees and the company (Briner, 1996).

In India the insurance does not cover musculoskeletal related costs against physiotherapy as there is a lack of awareness about the profession and the conditions and the impact of work related injuries and disorders.

Bank employees at different levels suffer chronic musculoskeletal injuries and deal with pain and continue to work without addressing proper postural and biomechanical consideration at work place.

This study adds on to the literature by providing the work related factors potentially contributing to musculoskeletal disability and pain. It adds on to the Indian research literature by providing the basic awareness about ergonomic awareness and stress management awareness in banks. It is a comprehensive prevalence study addressing the issue of musculoskeletal injuries in banks which can have a potential impact on quality of life of bank employees and an economic implication on the overall impact on the productivity in companies.

The awareness of this aspect is slowly gaining in corporate sector with health and wellness departments emerging in the corporate setup. This will have a potential impact on the role of physiotherapy in the corporate sector making therapist as leaders in managing work related injuries and becoming primary care practitioners in the area of work and health in the corporate industry.

\section{Subjects and Methods}

Inclusion of subjects

- $\quad$ Subjects who are involved in desk job.

- Minimum work experience of 1 year.

- Age group 21-60 years.

Exclusion of subjects

- With previous fractures/trauma/musculoskeletal disorder

- With any neurological disorder.

- Any psychological issues prior to starting this job.

\section{Procedure}

After taking an informed consent, a questionnaire based survey was conducted among 100 bank employees who fulfilled the inclusion criteria. Purpose of the survey was explained in detail. Components of the questionnaire and their relevance to survey was explained. A self-made questionnaire was taken to assess the prevalence of musculoskeletal discomfort and level of stress. After the data collection the same was coded, tabulated and analyzed using MS Excel.

\section{Results}

Contributing factor to pain (Figure 1)- Commonest factor which contributed to their pain was maintaining awkward posture (38\%) followed by performing overtime work (28\%). 


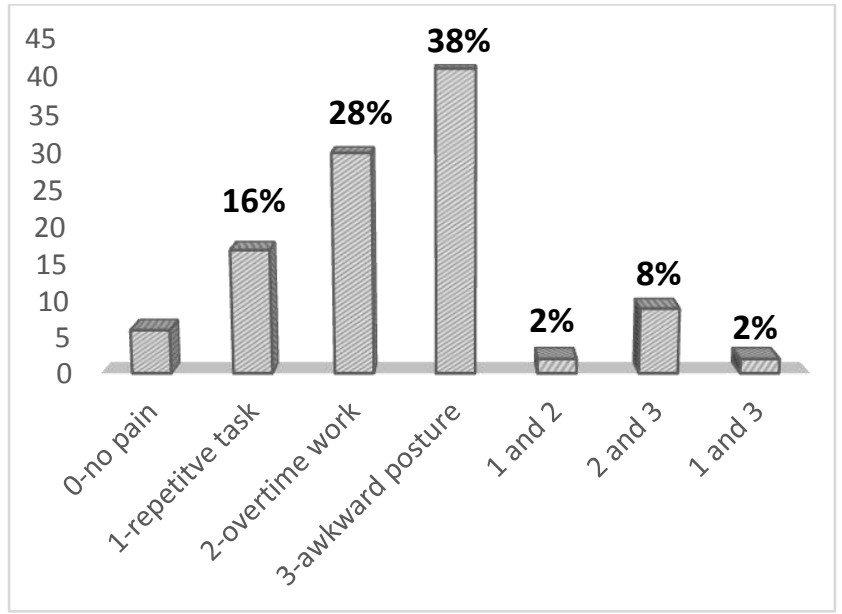

Figure 1

Work place stress scale (Figure 2)- 36\% of bank employees had moderate level of stress followed by $32 \%$ who had fairly low stress.

\section{WORK PLACE STRESS SCALE}

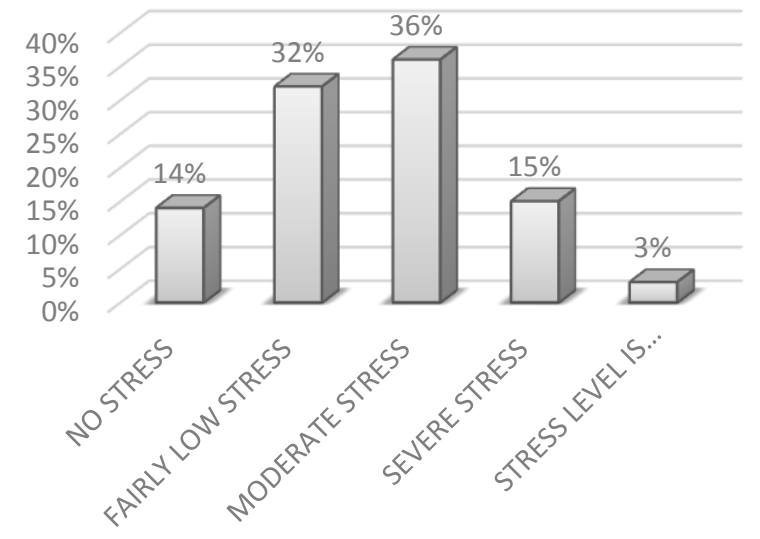

Figure 2

Common site of pain (Figure 3)-: Out of 91, 44\% of employees were prevented from doing their normal work because of neck pain followed by $31 \%$ of them because of upper back pain.

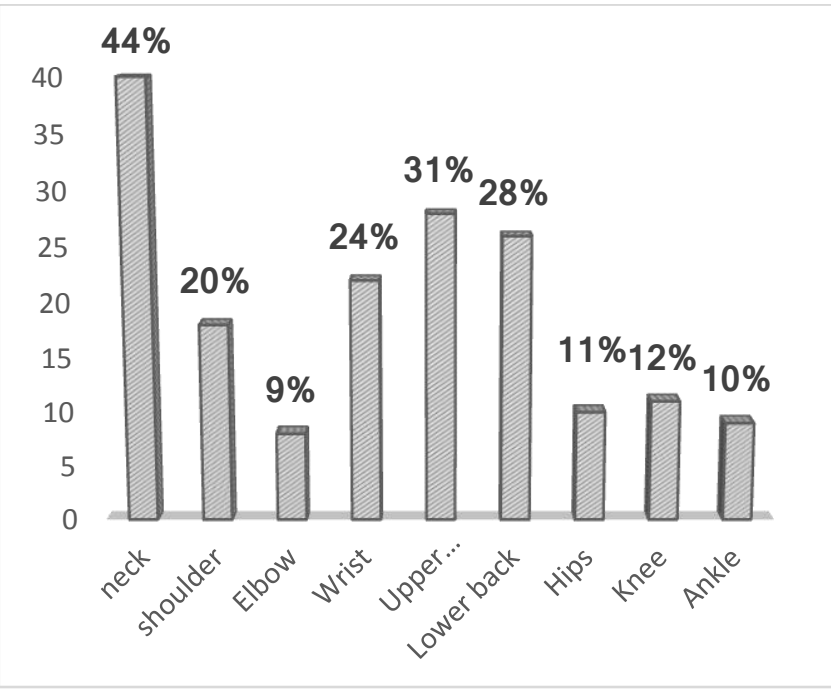

Figure 3

\section{Discussion}

Study was to find out the prevalence of musculoskeletal problems, personal factors and work related stress levels among bank employees.

Response to survey was $100 \%$ and all the questionnaires were filled completely.

Results of the study showed that there was high prevalence of musculoskeletal pain among bank employees (91\%).

Neck pain (67\%) followed by upper back (each $44 \%$ ) was the most identified. In this study participants found that using computer, overtime work, bending neck, computer typing, static loading all are responsible for their neck pain.

A positive relationship between fixed postures and musculoskeletal disorders (Akesson et al., 2000)

Holding extreme postures places very high loads on the body, resulting in rapid fatigue. The static postures add to the muscular effort required to do the task. The constricted blood flow reduces the supply of nutrients to the muscles and the removal of acids and other waste products away from the tissues. Reduced blood flow also slows down delivery of oxygen to the muscles. The longer or more frequently static loading occurs, the greater the risk of injury due to overuse of muscles, joints and other tissues.

Regular exercise may provide bankers with a break from their strenuous workload, and refresh and strengthen their bodies while also providing mental relaxation from the high psychological demands of the job. These effects probably interact to contribute to a better health status and a decreased risk of musculoskeletal symptoms.

Higher job demands (physical as well as psychological workload) were associated with increased musculoskeletal pain.

\section{Conclusion}

- There is high prevalence of musculoskeletal discomfort and the commonest site of pain being the neck region followed by upper back and lower back region.

- Awkward postures are most observed in this occupation.

- Moderate psychological stress among bank employees.

\section{References}

[1] L. Nunes, "FAST ERGO-X: a tool for ergonomic auditing and work-related musculoskeletal disorders prevention,"

Work, 2009. vol. 34, no. 2, 133-148.

[2] J. Abledu and G. Abledu, "Multiple logistic regression analysis of predictors of musculoskeletal disorders and disability among bank workers in Kumasi, Ghana," Journal of Ergonomics, 2012; vol. 2, article 111

[3] N. Magnavita, M. Elovainio, I. de Nardis, T. Heponiemi, and A. Bergamaschi, "Environmental discomfort and musculoskeletal disorders," Occupational Medicine, 2011; pg 196-201. 
[4] Woods V. Musculoskeletal disorders and visual strain in intensive data processing workers. Occup Med (Lond) 2005; 55: 121-127

[5] Cook C, Burgess-Limerrick R, Chang S. The prevalence of neck and upper extremity musculoskeletal symptoms in computer mouse users.

International Journal of Industrial Ergonomics2000, 26: 347-356.

[6] Janwantanakul P, Pensri P, Jiamjarasrangsri V, Sinsongsook T. Prevalence of self-reported musculoskeletal symptoms among office workers.

Occup Med (Lond) 2008; 58: 436-438.

[7] Klussmann A, Gebhardt H, Liebers F, Rieger MA. Musculoskeletal symptoms of the upper extremities and the neck: A cross-sectional study on prevalence and symptom-predicting factors at visual display terminal (VDT) workstations.

BMC MusculoskeletDisord2008; 9: 96.
[8] Korhonen T, Ketola R, Toivonen $\mathrm{R}$ et al. Work related and individual predictors for incident neck pain among office employees working with video display units. Occup Environ Med 2003; 60: 475-482.

[9] Brandao AG, Horta BL, Tomasi E. Signs of musculoskeletal disorders in bank workers from the city of Pelotas and region: prevalence and associated factors. Rev. Bras. Epidemiol2005; 8: 295-305.

[10] Akrouf QA, Crawford JO, Al-Shatti AS, Kamel MI. Musculoskeletal disorders among bank office workers in Kuwait.

East Mediterr Health J2010; 16: 94-100.

[11] Briner, R. B. ABC of work related disorders. Absence from work.

BMJ (Clinical Research Ed.), 1996; 313(7061), 874-877.

[12] Lacerda, E. M., Nácul, L. C., Augusto, L. G. D. S ET et al. Prevalence and associations of symptoms of upper extremities, repetitive strain injuries (RSI) and "RSI-like condition".

BMC Public Health2005, 5, 107. 